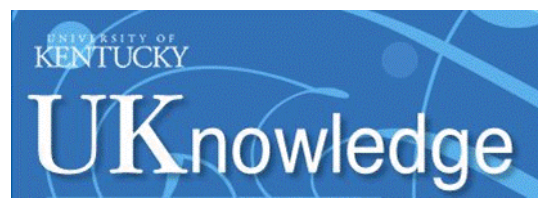

University of Kentucky

UKnowledge

\title{
Experiencing Physical Violence During Pregnancy: Prevalence and Correlates
}

Vilma E. Cokkinides

University of South Carolina

Ann L. Coker

University of South Carolina - Columbia, ann.coker@uky.edu

Follow this and additional works at: https://uknowledge.uky.edu/crvaw_facpub

Part of the Obstetrics and Gynecology Commons, Psychology Commons, Public Health Commons, Social Work Commons, and the Sociology Commons

Right click to open a feedback form in a new tab to let us know how this document benefits you.

\section{Repository Citation}

Cokkinides, Vilma E. and Coker, Ann L., "Experiencing Physical Violence During Pregnancy: Prevalence and Correlates" (1998). CRVAW Faculty Journal Articles. 132.

https://uknowledge.uky.edu/crvaw_facpub/132

This Article is brought to you for free and open access by the Center for Research on Violence Against Women at UKnowledge. It has been accepted for inclusion in CRVAW Faculty Journal Articles by an authorized administrator of UKnowledge. For more information, please contact UKnowledge@lsv.uky.edu. 


\section{Experiencing Physical Violence During Pregnancy: Prevalence and Correlates}

Notes/Citation Information

Published in Family \& Community Health, v. 20, no. 4, p. 19-37.

This manuscript provided with permission from the publisher, and also accessible through the journal's website at http://journals.Iww.com/familyandcommunityhealth/Abstract/1998/01000/

Experiencing_Physical_Violence_During_Pregnancy_.4.aspx/

Dr. Ann Coker had not been a faculty member of the University of Kentucky at the time of publication. 


\title{
Experiencing Physical Violence During Pregnancy: Prevalence and Correlates
}

\begin{abstract}
Violence during pregnancy directly impacts the mental and physical health of pregnant women. We assessed the prevalence and correlates of physical violence around the time of pregnancy in a representative sample of 6,718 women in South Carolina. Physical violence, defined as "being physically hurt by husband or partner" or "being involved in a physical fight" was reported by $10.9 \%$ of recently pregnant women. These were correlates of violence: experiencing increased numbers of stressful life events, being unmarried, having increased parity, being on Medicaid, and having an unwanted pregnancy. Screening to identify violence in pregnancy in health care settings is vital to maternal and child health. However, identifying violence is not enough; community resources and clinic-based support are needed to help women deal with violence in their lives. Key words: abuse, epidemiology, pregnancy, risk factor, violence, women
\end{abstract}

Vilma E. Cokkinides, MS, MSPH Research Associate-Epidemiologist Institute for Families in Society University of South Carolina

\author{
Ann L. Coker, PhD, MPH \\ Associate Professor \\ Department of Epidemiology and \\ Biostatistics \\ School of Public Health \\ University of South Carolina \\ Columbia, South Carolina
}

DaRTNER OR INTIMATE VIOLENCE is a serious social and public health problem for women and men in the United States. National survey estimates indicate that between 1.8 to 5 million women in intimate relationships are physically assaulted each year. ${ }^{1,2}$ In South Carolina alone, there were 24,665 reported incidents of criminal domestic assaults in 1993; $59 \%$ involved spouses, while $29 \%$ of all assaults reported to the police were allegedly perpetrated by someone related to the victim. ${ }^{3}$

When a pregnant woman is assaulted, two individuals are endangered: the woman herself and her unborn child. Although violence during pregnancy can have significant immediate and long term consequences, this violence continues to be underrecognized by the medical profession. ${ }^{4-6}$ However, the opportunity to identify partner violence and intervene is perhaps greatest during pregnancy as it

This research was funded by grant U50/CC407132 from the Centers for Disease Control and Prevention. 
is one of a few times that women routinely interact with health care systems. ${ }^{5}$

Clinical studies indicate that $4 \%$ to $17 \%$ of all women are abused during pregnancy. ${ }^{6-10}$ The Pregnancy Risk Assessment Monitoring System (PRAMS) population-based data on partner physical violence around the time of pregnancy from four states (Alaska, Maine, Oklahoma, and West Virginia) showed that the prevalence of a partner or husband physically hurting the surveyed women in the 12 months before delivery ranged from $3.8 \%$ to $6.9 \%$, depending on the state. ${ }^{11}$

A range of factors have been identified as correlates of being a victim of partner physical violence during pregnancy, thus underscoring the complexity of the issue of violence against women. These studies show that compared with women not reporting violence, those reporting partner violence were more likely to be poorer and from minority groups, to be less educated, to have more children, to not be married, and to receive social assistance. $6,9,12-19$

Studies have also indicated that pregnant women who have been physically assaulted were more likely to have unintended pregnancies, ${ }^{17}$ to delay initiation of prenatal care,, 9.14 .17 to suffer depressive symptoms, ${ }^{6-12}$ and to use substances such as tobacco, alcohol, or illicit drugs ${ }^{6,9,12-15,18.19}$ than their nonassaulted pregnant counterparts. Martin et al found that women physically assaulted during pregnancy were more likely to continue substance use during pregnancy than were nonassaulted women. ${ }^{20}$ All these factors may, in turn, adversely affect the health of mothers and infants.
In this population-based study of postpartum women, we sought to estimate the prevalence of partner physical violence and involvement in a physical fight in the 12 months before delivery. Further, we identified correlates of both partner violence and fighting. These correlates included sociodemographic characteristics, prenatal care participation, source and payer of prenatal care, unwanted pregnancy, psychosocial stress, and substance use before and during pregnancy.

\section{METHODS}

\section{Study population}

The South Carolina Pregnancy Risk Assessment Monitoring System (SCPRAMS) Project was initiated in 1993 through a collaborative agreement between the Centers for Disease Control and Prevention (CDC) and the state health department to collect populationbased data of selected maternal behaviors that occur before and around the time of pregnancy and into the child's early infancy. A stratified systematic sample of approximately 250 postpartum women having live births is drawn each month from the South Carolina birth certificate registry. Women with low birthweight infants $(<2,500 \mathrm{~g})$ and women residents from selected counties are oversampled. Selected participants are surveyed primarily by mail. To enhance response rates, the SCPRAMS used monetary incentives, attempted to contact women up to three times by mail, and finally used phone follow-up of nonrespondents. From January 1993 to 
April 1995, SCPRAMS surveyed 9,563 postpartum women, of whom 6,718 participated in the survey $70.2 \%$ response rate). The SCPRAMS survey data were linked to the birth certificate information of the corresponding participant's infant. Women were contacted 3 to 6 months postpartum.

From unweighted analyses, we determined that nonrespondents differed significantly from respondents on sociodemographic factors. As compared with respondents, nonrespondents were significantly more likely to be minority women (non-white), to have no more than 12 years of education, and to be unmarried $(p<0.0001$ ). Therefore, SCPRAMS data were weighted to account for sampling probabilities and for nonresponse differentials by maternal sociodemographic status. The computer software program Survey Data Analysis (SUDAAN) was used to calculate weighted distributions that reflected selection and response probabilities for the survey design.

\section{Measures of physical violence around the time of pregnancy}

We classified physical violence experienced around the time of pregnancy using two questions from the SCPRAMS survey: (1) Was the woman involved in a physical fight in the last 12 months before delivery? and 2) was the woman physically hurt by a husband or partner (partner physical violence) in the last 12 months before delivery? Of the 6,718 respondents, $1.7 \%$ (115 women) were excluded from analyses because of missing data on any of these questions. In

\section{Two thirds of women who responded that they had been hurt by a partner also responded that they had been in a physical fight during the 12 months before delivery.}

these analyses we looked exclusively at physical violence around the time of pregnancy. We have no data on the severity, timing, and frequency of the physical violence nor do we have information on other types of violence (eg, sexual or emotional violence) experienced around the time of pregnancy. We cannot distinguish women chronically battered by a partner from women involved in one fight around the time of pregnancy or in the three months before conception. Undoubtedly the exposure group includes chronically battered women who are physically, sexually, and emotionally abused as well as women who have fought with a partner only once. These two sets of experiences are qualitatively different both in terms of the short- and long-term physical and psychological risk to mothers and infants. Battered women often experience emotional violence and sexual violence in addition to chronic physical violence.

In this analysis, we conceptualize physical violence around the time of pregnancy in the following way to differentiate partner violence from fighting only around the time of pregnancy. We include those experiencing "partner physical violence" to be those women who responded that they were "physically hurt by their husband or partner during the 
12 months before delivery." Two thirds of women who responded that they had been hurt by a partner also responded that they had been in a "physical fight during the 12 months before delivery." Because the latter statement did not further identify with whom the woman fought, we could not distinguish whether the fight was with a partner or someone else. However, partner physical violence and fighting around the time of pregnancy were highly correlated. But what of the women reporting being in a physical fight around the time of pregnancy but not reporting being hurt by a partner? These are women who clearly report physical violence around the time of pregnancy (being in a physical fight) but not partner violence. They may be women fighting with (1) partners but do not consider themselves "hurt," (2) men with whom they have been intimate yet they do not consider to be partners (ie, dates), or (3) someone else altogether (eg, friends, family members, acquaintances, or strangers). In this analysis, we hope to characterize this group of women experiencing physical violence yet not reporting partner physical abuse by comparing the prevalence and correlates for this group with those for women reporting partner physical abuse.

\section{Importance of the interview setting}

Asking about physical violence in the context of an intimate relationship is difficult at best. Not only must the right questions be asked, but the interview setting must be conducive to reporting partner violence. As with any sensitive topic, the rate at which the event is reported increases with increasing privacy of the interview and with the trust and support that women are given in the interview setting. Providing a safe environment for women to report violence is crucial to obtaining accurate data and ensuring that women are not further hurt by study participation. Gazmarian ${ }^{17}$ compared the frequency of reporting violence around the time of pregnancy, from the range of published studies, by the interviewing setting and population studied. She reports that rates are highest for in-person interviews, followed by telephone interviews and mailed surveys. In PRAMS, questionnaires are self-administered and interviewer administered in telephone surveys. We may be getting a disproportionate number of reports of past partner violence as women currently in abusive relationships may not (or cannot) report this in a mailed or telephone survey if the partner lives with the woman.

\section{Correlates}

Because we are using cross-sectional data we cannot establish a temporal sequence between a given factor and subsequent risk of violence in women. We then are using the term correlate to refer to a factor that may be a risk factor or a consequence of violence. We cannot, however, distinguish the direction of these associations.

Information on correlates of physical violence was derived from the SCPRAMS record and linked birth certificate record. The former source provided data on poverty status, household crowding, Medicaid coverage around the time of preg- 
nancy, source of prenatal care, smoking and alcohol use during the three months before getting pregnant and during the last trimester of the pregnancy, pregnancy intendedness at conception, and experiencing stressful life events during the 12 months prior to delivery. The women with missing data for any of the previously mentioned variables (ranging from $0.08 \%$ for mother's age to $7.8 \%$ for pregnancy intendedness) were excluded from analyses.

Life events were grouped into three sets:

1. relationship or legal stressors (marital separation, divorce, being homeless, being arrested, being charged for an offense, husband or partner sent to jail, or having a partner with substance abuse problem);

2. personal loss or grief (death of either the husband or partner, death of a close family member, death of a friend, or a close family member attempting suicide), and;

3 , financial stressors (husband or partner lost his job, woman lost her job, or woman got into heavy debt). Each set represents interrelated stressors that allow us to look at different dimensions of stressful events and violence. Previous research has found that certain psychosocial stressors are more characteristically associated with physical violence victimization. ${ }^{21}$

We compared women who reported that their pregnancy was unwanted (at conception) with those who responded that the pregnancy was wanted and those wanting the pregnancy sooner or later (pregnancy intendedness).
To assess the combined use of substances (cigarettes and alcohol) during the three months before pregnancy and during the last trimester, women were categorized as using neither substance, using both substances if they reported using cigarettes and alcohol, or using either substance during the three months before pregnancy or during the last trimester. As the results of our analyses were similar for substance use before pregnancy and in the last trimester, only the results for substance use in the last trimester are presented.

The poverty level was determined using the total household income in the 12 months before delivery by family size. Poverty status was determined by US poverty threshold guidelines. ${ }^{22}$ The total number of persons living in the household and their assigned income levels were compared with corresponding poverty thresholds in 1993,1994, and 1995. For example, a mother living in a four-person household with a household income of $\$ 14,450$ in $1993, \$ 14,800$ in 1994 , or $\$ 15,150$ in 1995 would be considered as living at $100 \%$ of the poverty rate. Women were categorized as "poor" at less than $100 \%$ of poverty level, "near poor" at 100\%-185\% of poverty level, and "nonpoor" at more than $185 \%$ of poverty level.

The birth record provided information on the mother's race, education, marital status, parity, trimester in which prenatal care was initiated, and number of prenatal care visits. The Kessner index was used to assess women's participation in prenatal care ${ }^{23}$; the index assesses prenatal care adequacy based on the month prenatal care began and number of pre- 
natal care visits adjusted for length of gestation.

SUDAAN ${ }^{24}$ simple categorical analyses were used to estimate the prevalence of physical violence status during the 12 months before delivery and the weighted distribution of correlates by physical violence status. The weighted distribution adjusts for selection and response probabilities of the survey design. Logistic regression analyses within SUDAAN were used to examine the variation among the associations between prevalence of physical violence status (two groups) and each selected correlate. Hence, the prevalence odds ratio (POR) and 95\% confidence intervals $(95 \% \mathrm{CI})$ for each correlate on the same outcomes (partner physical violence and being involved in a physical fight but not reporting partner violence) were compared in order to determine relative independent effects. Mother's age and poverty level were two important covariates included in all adjusted logistic regression models.

\section{RESULTS}

\section{Prevalence of violent events around the time of pregnancy}

From these SCPRAMS data, we estimated that $5.9 \%$ of recently delivered women had been in a physical fight during the past 12 months and were not hurt by a partner, $3.6 \%$ had been both involved in a physical fight and were physically hurt by a husband or partner, and $1.5 \%$ had only been physically hurt by a partner but were not involved in a physical fight. The overall prevalence of physical violence (having either event) experienced around the time of pregnancy was $10.9 \%$ while the prevalence of partner physical violence was $5.1 \%$ (Table 1).

Of the women who experienced either partner violence or being in a fight "only" (10.9\% of the SCPRAMS sample), 54\% were involved in a physical fight but were not physically hurt by a partner, $33 \%$ were involved in a physical fight and were physically hurt by a partner, and $13 \%$ were physically hurt by a partner but were not in a physical fight. The weighted population estimates from the sample indicated that approximately 5,700 postpartum women had been either physically hurt by a husband or partner $(\mathrm{n}=2,622)$ or involved in a physical fight ( $n=3,078$ ) each year in South Carolina.

\section{Characteristics of women having live births in the SCPRAMS sample}

The sociodemographic characteristics of women who delivered live births in South Carolina and who reported experiencing violence in the 12 months before delivery are presented in Table 2 . Briefly, when compared with women reporting no violence, women reporting fighting only were more likely to be younger, African American, nulliparous and single; to have less than a high school education; to live below the poverty line $(<100 \%)$; to have less than adequate prenatal care, higher numbers of stressful life events; to have an unwanted pregnancy; and to use alcohol or cigarettes during pregnancy. Similarly, when compared with women reporting no violence, women reporting partner physical 
Table 1. Distribution of violent events during 12 months preceding delivery among a population-based sample of South Carolina postpartum mothers delivering live births in 1993-1995

\begin{tabular}{|ccc|}
\hline & $\begin{array}{c}\text { Unweighted number } \\
\mathbf{( N = 6 , 7 1 8 )}\end{array}$ & $\begin{array}{c}\text { Weighted } \\
\text { \% }\end{array}$ \\
\hline $\begin{array}{l}\text { Prevalence of physical violence during pregnancy } \\
\text { Involved in a physical fight during pregnancy } \\
\text { Physically hurt by a husband or partner during } \\
\quad \text { pregnancy }\end{array}$ & 604 & 9.4 \\
$\begin{array}{l}\text { Overlapping definitions of physical violence during } \\
\text { pregnancy }\end{array}$ & 348 & 5.1 \\
$\begin{array}{l}\text { Involved in a physical fight or physically hurt by } \\
\quad \text { a husband or partner } \\
\text { Involved in a physical fight; not physically hurt } \\
\quad \text { by a husband or partner }\end{array}$ & 707 & 10.9 \\
$\begin{array}{l}\text { Physically hurt by a husband or partner; not in a } \\
\text { physical fight }\end{array}$ & 359 & 5.9 \\
$\begin{array}{l}\text { Physically hurt by a husband or partner and in a } \\
\text { physical fight }\end{array}$ & 103 & 1.5 \\
\hline
\end{tabular}

violence were more likely to be younger, African American and single; to have less than a high school education; to live below the poverty line $(<100 \%)$; to have less than adequate prenatal care, higher numbers of stressful life events, and an unwanted pregnancy; and to use alcohol or cigarettes during pregnancy.

For all women independent of the type of violence experienced, $47 \%$ of the women were at $100 \%$ of poverty while $33 \%$ have household income above the $185 \%$ of poverty threshold; $54 \%$ of the women were on Medicaid around the time of pregnancy; $68 \%$ of the women received their prenatal care from a private doctor; two in three women (61\%) had a high school level education or less; $62 \%$ of the women were married; $59 \%$ were white, while $41 \%$ were black (39\%) and other races (2\%); $17 \%$ of the women were younger than 20 years while $83 \%$ of the women were age 20 or older (data not shown in Table 2).

\section{Correlates of physical violence around the time of pregnancy}

Table 3 provides the prevalence rate for experiencing either being hurt by a partner (partner physical violence) or being in a physical fight but not being hurt by a partner. The prevalence odds ratios (POR) for each correlate presented in Table 2 and the two sets of violence categories are provided; these estimates were adjusted for the mother's age and poverty level. 
Table 2. Distribution of maternal socioeconomic correlates among SCPRAM sample, 1993-1995, by violence experienced in the 12 months before delivery

\begin{tabular}{|c|c|c|c|}
\hline \multirow[b]{2}{*}{ Correlate } & \multicolumn{3}{|c|}{ \% Respondents reporting } \\
\hline & $\begin{array}{l}\text { No violence } \\
(\mathrm{N}=5,896)\end{array}$ & $\begin{array}{c}\text { Partner physical } \\
\text { violence ( }=348)\end{array}$ & $\begin{array}{c}\text { Physical fight } \\
\text { only (N = 359) }\end{array}$ \\
\hline \multicolumn{4}{|l|}{ Age, yr } \\
\hline $18-19$ & 17.1 & 23.9 & 45.1 \\
\hline $20-29$ & 53.3 & 57.5 & 44.3 \\
\hline $30-45$ & 29.6 & 18.6 & 10.6 \\
\hline \multicolumn{4}{|l|}{ Race } \\
\hline African-American & 44.8 & 55.5 & 67.1 \\
\hline White & 55.1 & 44.5 & 32.9 \\
\hline \multicolumn{4}{|l|}{ Marital status } \\
\hline Currently married & 61.2 & 43.7 & 22.8 \\
\hline Currently single & 38.8 & 56.3 & 77.1 \\
\hline \multicolumn{4}{|l|}{ Education } \\
\hline $0-11$ yr & 21.2 & 34.8 & 45.6 \\
\hline GED or high school graduate & 40.2 & 47.4 & 38.0 \\
\hline $\begin{array}{l}\text { Beyond high school } \\
\text { Poverty level }\end{array}$ & 38.6 & 17.8 & 16.4 \\
\hline$\leq 100$ & 49.1 & 74.7 & 78.7 \\
\hline $100-185$ & 19.7 & 15.3 & 14.1 \\
\hline$>185$ & 31.2 & 10.0 & 7.2 \\
\hline \multicolumn{4}{|l|}{ Parity } \\
\hline Nulliparous & 47.5 & 38.8 & 55.0 \\
\hline 1 child & 32.6 & 31.0 & 29.0 \\
\hline 2 children & 13.7 & 18.4 & 10.7 \\
\hline 3 or more children & 6.2 & 11.8 & 5.3 \\
\hline \multicolumn{4}{|l|}{ Source of prenatal care } \\
\hline Public & 28.9 & 42.7 & 53.3 \\
\hline Private & 71.1 & 57.3 & 46.7 \\
\hline \multicolumn{4}{|l|}{$\begin{array}{l}\text { Prenatal Care Adequacy } \\
\text { (Kessner) }\end{array}$} \\
\hline Adequate & 65.2 & 53.7 & 51.5 \\
\hline Intermediate & 25.8 & 32.6 & 35.8 \\
\hline Inadequate & 9.0 & 13.7 & 12.7 \\
\hline \multicolumn{4}{|l|}{ Number of stressful life events } \\
\hline$>5$ & 2.6 & 23.3 & 12.5 \\
\hline $4-5$ & 8.9 & 25.0 & 27.9 \\
\hline $2-3$ & 27.8 & 34.2 & 34.5 \\
\hline $0-1$ & 60.7 & 17.5 & 25.1 \\
\hline
\end{tabular}


Table 2. Continued

\begin{tabular}{|lccc|} 
& \multicolumn{3}{c|}{ \% Respondents reporting } \\
\cline { 2 - 4 } Correlate & $\begin{array}{c}\text { No violence } \\
\mathbf{( N = 5 , 8 9 6 )}\end{array}$ & $\begin{array}{c}\text { Partner physical } \\
\text { violence (N = 348) }\end{array}$ & $\begin{array}{c}\text { Physical fight } \\
\text { only (N = 359) }\end{array}$ \\
\hline Pregnancy intendedness & & & \\
Unwanted & 12.8 & 21.0 & 26.8 \\
$\quad$ Wanted and mistimed & 87.2 & 79.0 & 73.2 \\
Cigarette or alcohol use during & & & \\
last trimester & & 4.0 & 2.1 \\
Both cigarettes and alcohol & 1.3 & 30.2 & 20.6 \\
Either cigarettes or alcohol & 16.7 & 65.8 & 77.3 \\
Neither cigarettes nor alcohol & 82.0 & & \\
\hline
\end{tabular}

\section{Correlates of partner physical violence}

The prevalence of partner physical violence was greater for women who were younger, non-white, single, poor, not college educated, on Medicaid and multiparous; got prenatal care from public sources; had less than adequate prenatal care and an unwanted pregnancy; used cigarettes or alcohol both prior to and during pregnancy; and experienced increasing numbers of stressful life events. When adjusted for age and poverty, only being on Medicaid, increasing parity, increasing number of stressful life events, and cigarette or alcohol use were associated with partner physical violence. Both increasing parity and increasing numbers of stressful life events were associated with partner physical violence in a dose-response fashion: increasing rates of partner physical violence with increasing levels of stress and increasing parity. Women reporting more than five stressful life events were
17.1 times more likely to report partner violence than were those reporting only one or no stressful life events during pregnancy.

We further explored the types of stressful life events most strongly associated with partner physical violence. The first set included the following relationship or legal stressors: marital separation or divorce, being homeless, arrested, or charged for an offense; and having a husband or partner sent to jail or with a substance abuse problem. Women reporting three or more from this stressful life events set were 6.4 times more likely to
When adjusted for age and poverty, only being on Medicaid, increasing parity, increasing number of stressful life events, and cigarette or alcohol use were associated with partner physical violence. 


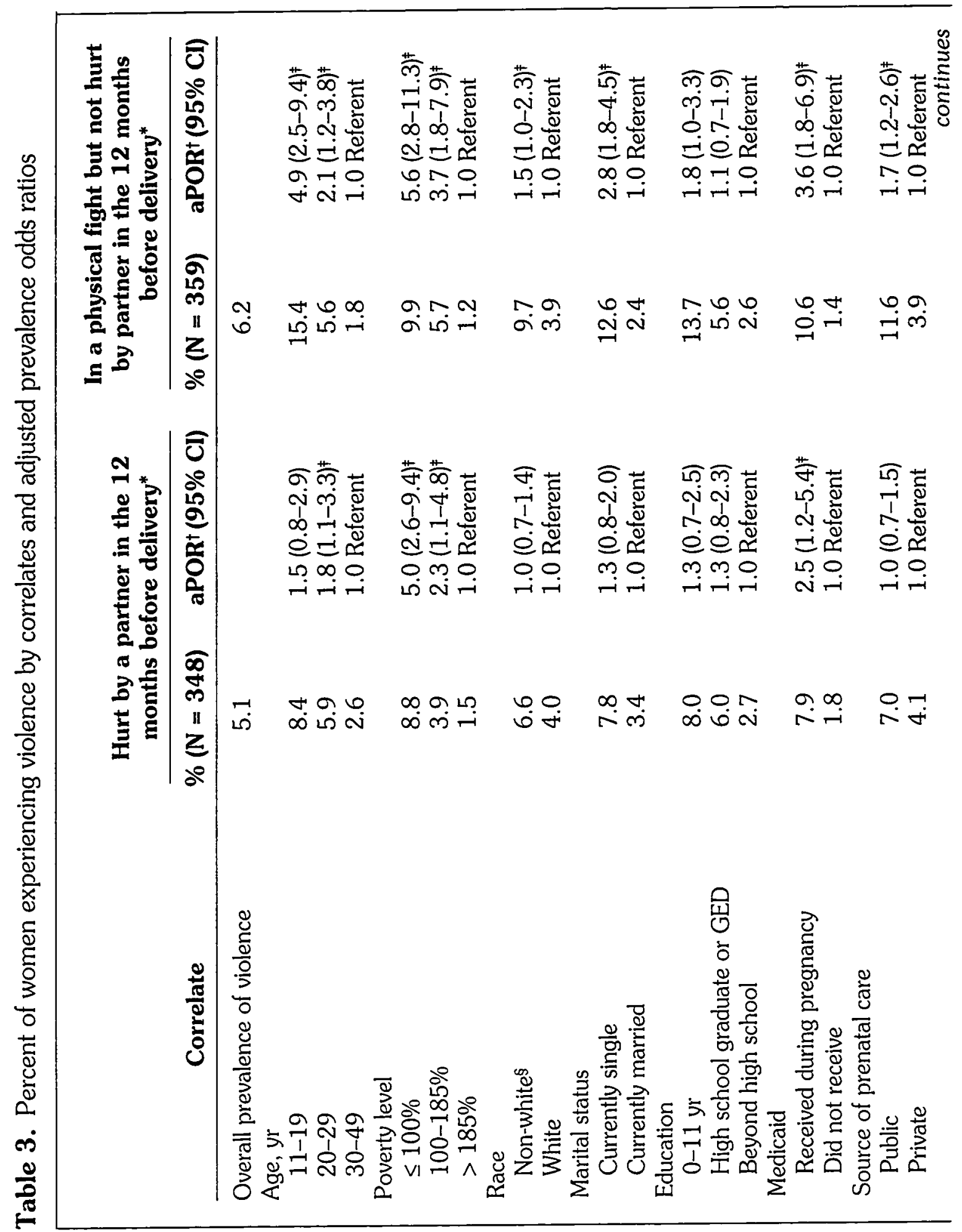




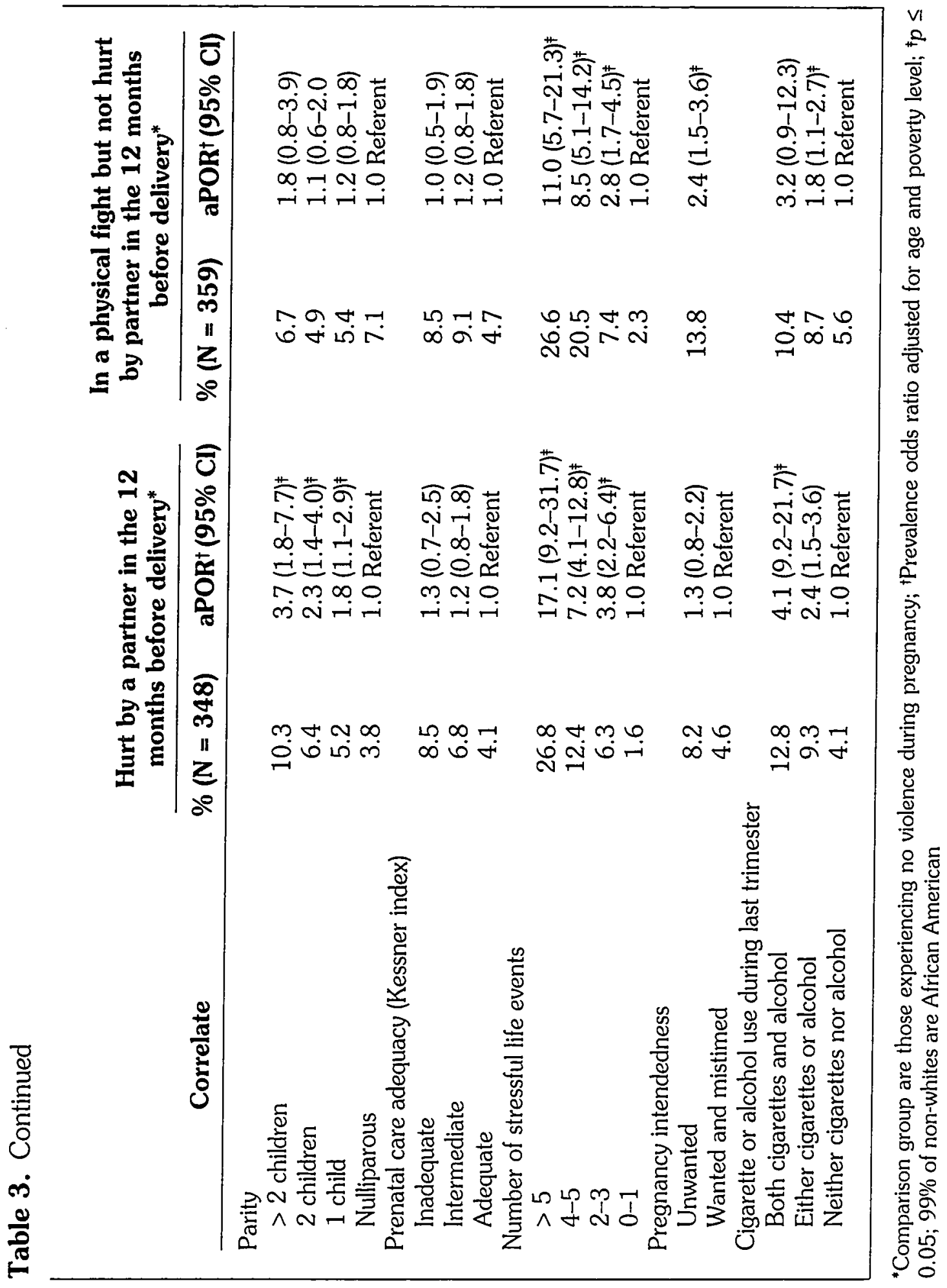


also report partner violence $(95 \% \mathrm{CI}$ : 3.8-9.9). The second set of stressful life events included loss or grief events: death of either the husband or partner, death of a close family member, death of a friend, or a close family member attempting suicide. Women reporting three or more of these events were 6.2 times $(95 \% \mathrm{CI}$ : 1.9-19.7) more likely to also report partner violence. The last set of stressful events were those impacting a woman's financial situation: husband or partner lost his job, woman lost her job, or woman got into heavy debt. Women reporting more than one of these three events were 3.9 times (95\% CI: 2.8-5.7) more likely to also report partner violence. Substance abuse (cigarette smoking and alcohol drinking) during the three months before pregnancy (data not in Table 3) and during the last trimester of pregnancy were significantly associated with partner physical violence around the time of pregnancy. Cigarette smoking both prior to and during pregnancy was associated with partner violence; the same was true for alcohol use (not in Table 3).

When age, poverty, being on Medicaid, stressful life events, parity, and substance use were all included in a model with partner physical violence around the time of pregnancy as the dependent variable, all remained significantly associated with partner physical violence. Stressful life events remained the strongest correlate of partner violence around the time of pregnancy; the addition of substance use and parity did little to diminish the strength of the association between stressful life events and partner physical violence.

\section{Correlates of being in a "physical fight only" around the time of pregnancy)}

The prevalence of being in a fight around the time of pregnancy but not reporting partner violence was greater for women who were younger, non-white, single, poor, less educated, on Medicaid, got prenatal care from public sources, received less than adequate prenatal care, had an unwanted pregnancy, used cigarettes or alcohol both prior to and during pregnancy, and experienced increasing numbers of stressful life events. When adjusting for age and poverty the following remained associated with being in a "fight only": being non-white (POR $=1.5$ ), being single (POR 2.8), having less than a high school education (POR $=$ 1.8 ), being on Medicaid ( $P O R=3.6$ ), getting prenatal care from public sources $(\mathrm{POR}=1.7)$, having an unwanted pregnancy (POR $=2.4$ ), using cigarettes or alcohol during pregnancy, and experiencing increased numbers of stressful life events. Increasing parity was not associated with being in a "fight only" around the time of pregnancy.

When exploring the types of life events associated with being in a "fight only," we found that the relationship and legal stressors were strongly associated with fights $(\mathrm{POR}=4.2$ for reporting three or more of seven events). The magnitude of the association between the relationship or legal stressor and fighting only was smaller ( $P O R=4.2$ ) than that for partner physical violence $(\mathrm{POR}=6.4)$. The four loss or grief events were also associated with fighting $(\mathrm{POR}=4.9)$ and partner violence $(\mathrm{POR}=5.9$ ) as were the three 
financial impact stressors for fighting $(\mathrm{POR}=3.6)$ and partner violence $(\mathrm{POR}$ $=3.8$ ).

When age, poverty, race, marital status, Medicaid status, pregnancy intendedness, stressful life events, and substance use were all included in a model "with fighting but no partner violence" as the dependent variable, substance use (cigarettes and alcohol) and race were no longer significantly associated with this aspect of violence around the time of pregnancy. Women younger than 20 were 4.5 times more likely to be involved in fights around the time of pregnancy than were women aged 30 and older. Stressful life events remained the strongest correlate of being in a "fight only" around the time of pregnancy.

\section{DISCUSSION}

From the population estimates of the SCPRAMS survey for 1993-1995 we find that $5.1 \%$ of women who delivered live births reported that a husband or partner had physically hurt them during the 12 months before childbirth. This finding is consistent with reported estimates from other non-population-based studies $6,8,9,16,18$ and is directly comparable to the larger study using national PRAMS data. II However, we believe that this $5.1 \%$ estimate of partner violence around the time of pregnancy is an underestimate and that the more accurate prevalence of partner violence around the time of pregnancy includes another $5.9 \%$ of women involved in a physical fight but not reporting being "physically hurt by a husband or partner." From our analyses, we sought to address who these women are and whether the correlates of being in a fight only are also correlates of partner physical violence around the time of pregnancy.

\section{Underestimating physical violence around the time of pregnancy}

If we include all physical violence around the time of pregnancy (rate of $10.9 \%$ ), more than $50 \%$ did not report being hurt by a partner. Clearly not all women who are in a physical fight around the time of pregnancy are hurt or injured. However, there is a potential for injury, depending with whom a woman fights. Given that two thirds of women reporting partner violence also report being in physical fights around the time of pregnancy, it is probable that some women not reporting partner violence have fought with male partners but were either not physically hurt or did not consider the person they fought with to be a partner. If this is the case, we may be underestimating partner violence in PRAMS analyses by excluding women in physical fights but not reporting being physically hurt by a partner. Further, PRAMS may underestimate physical violence by partners by requiring that women report being hurt. Most women who are physically assaulted are not injured or hurt.

One way to explore whether those reporting being in physical fights are a subset of those experiencing partner physical violence is to compare and contrast our findings regarding the correlates of both sets of physical violence around the time of pregnancy (Table 3). Because we are using the same comparison or non- 
exposure group (those experiencing no violence), we can directly compare those correlates for partner violence and those for physical fighting only. We also created full logistic models (separately for partner violence and physical fights only) and included all correlates of these two types of violence (from results presented in Table 3). For partner violence, the full model included maternal age, poverty level, parity, Medicaid status, number of stressful life events, and substance use during the last trimester of pregnancy. For being in a physical fight only, the full model included age, poverty level, race, current marital status, pregnancy intendedness, number of stressful life events, and substance use during the last trimester of pregnancy. Like those experiencing partner violence, those reporting physical fight yet no partner violence are more likely to be younger, to live in poverty, and to report greater numbers of stressful life events. In contrast with those reporting partner violence, the following were significantly associated with being in physical fight but not with partner violence: having an unwanted pregnancy and being single. Race and substance use during pregnancy were no longer statistically significant in the full model including all correlates for being in a physical fight.

In an effort to explore with whom had the women reporting being in "physical fights but not being hurt by a partner" actually fought, we compared changes in marital status during pregnancy. Among women reporting physical fights only, $51.2 \%$ were separated and $9.5 \%$ were divorced compared with $63.7 \%$ being separated among those reporting partner violence and $10.5 \%$ being divorced.
However, among those reporting no violence during pregnancy, only $15.5 \%$ were separated and $2.8 \%$ were divorced. Those reporting being in a physical fight but not experiencing partner violence are quite similar to those reporting partner violence in terms of marital separation and divorce and these two groups of women clearly differ from those reporting no violence. This suggests that women reporting being in fights only may be reporting violence with former partners (no longer married), not current violence. As a result, these women would be less likely to say that they were hurt by a husband or "current" partner.

The biggest difference between these two groups of women experiencing violence around the time of pregnancy may be a function of age. Among those reporting fighting but no partner violence, $76 \%$ were younger than age 25 (mean age $21 \pm 0.6$; range 13-49) compared with $67 \%$ being older than 25 among those reporting physical violence (mean age $23 \pm 0.6$; range 15-41); among those reporting no physical violence around the time of pregnancy, only $43 \%$ were younger than age 25 (mean $26 \pm$ 0.2 ; range 11-48). Younger age is significantly associated with reporting being in a fight (POR $=4.9$ ) for age less than 20 years, whereas age was not significantly associated with reporting physical violence (Table 3). Marital status was not associated with partner violence after adjustment for age and poverty status, yet being single remained strongly associated with being in a physical fight after adjusting for age and poverty status.

Younger women may disproportionately be reporting physical fights around 
the time of pregnancy (which involve dating partners or past partner) as fights only and not "current" partner violence. They may not perceive this physical violence to be with a partner or more specifically with the baby's father. Our term, partner, may result in underestimating intimate violence as women may not perceive that the person they fought with was a partner or the baby's father. It remains possible that women could have fought with those other than male intimate partners. However, similarities in the profiles of those reporting partner violence and physical fights suggests that this may not be a common occurrence. ${ }^{2}$

\section{Stressful life events and physical violence}

The first set. of stressful life events categorized as relationship or legal stressors were, as anticipated, strongly associated with both fighting and partner physical violence; these stressors are in fact known consequences of battering. Similarly, we found that the financial stressors (eg, job loss or heavy debt) were associated with both fighting and partner violence. Financial problems often occur around separation and divorce. Interestingly, we also found that personal loss or grief stressors were associated with fighting and partner violence. We did not hypothesize that this set of stressors would be associated with experiencing violence as these stressors are not direct or indirect consequences of physical violence. When we explored which specific stressful event was most strongly associated with violence, we found that a suicide attempt $(\mathrm{POR}=3.0)$ was the only loss or grief event signifi-
We found that the financial stressors (eg, job loss or heavy debt) were associated with both fighting and partner violence.

cantly associated with partner violence. $A$ death of the friend (POR $=2.9$ ) was the only loss or grief event significantly associated with being involved in a fight only. Women experiencing violence (either fighting or partner violence) are significantly more likely to also experience the death or attempted suicide of someone close to them. From these cross-sectional data we cannot establish a temporal sequence to these events. Perhaps women experiencing violence around the time of pregnancy are involved with friends or partners who are likewise at risk of physical or psychological dysfunction. This could explain the association with attempted suicide of a close friend or family member and partner violence. Violence may be a commonplace experience, thus, using violence as a way to resolve conflict becomes more acceptable.

\section{SUMMARY OF FINDINGS}

Key findings of this study were the highly significant relationships between physical violence around the time of pregnancy (being involved in a physical fight, or being physically hurt by husband or partner) and a high proportion of stressful life events. More important, the prevalence of physical violence was significantly higher among women who had also particular combinations of stressors 
(divorce, legal troubles, or drug violence; loss of job or financial debt; and death among family members or friends). Associations between physical violence and these three typologies of stressors may help characterize the social context in which stress occurs in the lives of women affected by physical violence around the time of pregnancy. Although not fully understood, stress during pregnancy has been associated with poorer birth outcomes. ${ }^{25}$ Therefore, the compound effect of experiencing violence with other stressors may detrimentally affect the overall physical and mental health of the woman during pregnancy.

\section{COMPARISON WITH THE LITERATURE}

Previous studies have shown variability by race in the rates of violence against women during pregnancy. $12,13,17$ This race differential in rates of violence during pregnancy may be explained by other factors such as socioeconomic status. ${ }^{26}$ When controlling for age, poverty, and stressful life events, we found that race was not associated with partner violence or being in a physical fight. Physical violence against pregnant women clearly cuts across racial lines. This study's findings also suggest that, even after controlling for poverty level, the prevalence of physical violence around the time of pregnancy was higher among women who were covered by Medicaid and those obtaining prenatal care through public sources. Similar findings have been reported in other studies.6.15 The clear implication of these findings is that con- cerned health care providers from the public sector (eg, health departments or community clinics), and health care providers who treat Medicaid-insured pregnant women should recognize that physical violence is a particularly relevant problem among the women they serve. All health care providers need to consistently and appropriately screen for physical violence and implement initiatives that protect and provide violence relief to victims of physical violence.

Similar to previous research, $15,17,18$ we did find a higher prevalence of physical violence among women with unwanted pregnancies and among women delaying entry into prenatal care. However, after controlling for age, poverty, and number of stressful life events these associations were no longer statistically significant. Violence, victimization, and control of women's lives by a partner may hamper a woman's ability to fulfill her reproductive plan. This in turn results in unplanned births and unwanted pregnancies; and, as this study and others studies suggest, 9,15,17,19 women with unintended pregnancies are more likely to delay participation in prenatal care. Although we cannot establish the temporal sequence between substance use and physical violence, it is clear from our data that women reporting physical violence around the time of pregnancy are more likely to also report cigarette or alcohol use before or during the last trimester of pregnancy. Clearly, prenatal care providers and substance abuse counselors need to recognize the potential link between substance use during pregnancy and physical violence. Addressing the violence in women's lives may have an im- 
portant impact in successfully treating substance abuse. Further research is needed to elucidate the temporal sequence between maternal substance use and physical violence around the time of pregnancy. For women experiencing physical violence, practicing healthful behaviors for a positive pregnancy outcome may not be a high priority.

\section{LIMITATIONS}

As noted in the methods, we were able to assess physical violence during the 12 months before delivery. We cannot distinguish chronic abuse from one fight. We are therefore including in our exposed group women who have experienced severe abuse with those involved in mutual fights. Further, although the PRAMS questions regarding "physically being hurt by a husband or a partner" and "being involved in a fight" are widely used in several states, these questions have not been evaluated as to their validity or reliability. Further, for the 12 months of recall we cannot distinguish between the violence occurring during pregnancy and the violence occurring in the three months before conception. Therefore, these data cannot be used to indicate whether pregnancy is a high risk time for assault since we have data only for the 12-month period before delivery. As noted in the methods, this questionnaire was self-administered presumably in respondents' homes; we may therefore be underestimating reporting of partner violence as women chronically experiencing this violence may be unwilling to complete the survey or likely to specifically not report partner violence.
Due to lack of data on social networks of the mother, this study could not control for the role of social support in ameliorating adverse pregnancy outcomes. ${ }^{27}$ Furthermore, the data on physical violence experienced around the time of pregnancy may be limited due to stigma attached to one's victimization and the private nature of the event. Because of diminished self-esteem, self-blaming, sense of terror, and depression, women trapped in a cycle of domestic violence are reluctant to disclose their victim status to family members and providers of health, social, and other services. ${ }^{2,21}$ Finally, the findings reported in this study are only generalizable to women whose pregnancies resulted in live births and not to those women with other pregnancy terminations (induced or elective abortions).

In an effort to better characterize physical violence around the time of pregnancy, the SCPRAMS was revised in 1996. Questions were changed to address physical violence perpetrated by someone known to the woman during the year before the delivery. Women are now being asked about (1) behavior-specific potentially hurtful acts such as pushing, hitting, slapping, or kicking; (2) physical violence before or around the time of pregnancy; and (3) the woman's relationship with the perpetrator (eg, husband or partner, family or household member, friend, or someone else). Women are also being asked whether, relative to the past year, physical violence during this pregnancy occurs more frequently, at about the same frequency, or less frequently. The question regard- 
ing "being in a physical fight around the time of pregnancy" remains in the 1996 SCPRAMS questionnaire. From these additions to SCPRAMS, we will have a better characterization of partner physical violence around the time of pregnancy.

Future research needs to precisely address the temporal sequence among these correlates of violence experienced during pregnancy and further elucidate pathways in which they affect birth outcomes and maternal morbidity. With these data, we can better plan strategies for identifying violence and targeting interventions to reduce adverse outcomes.
Violence against women is a societal problem that has major public health implications and important medical consequences. ${ }^{28}$ As this study demonstrates, almost $10 \%$ of recently pregnant women from the general population of reproductive age women report experiencing physical violence. To address this important public health issue, communitywide primary prevention programs that link health care providers, law enforcement, and shelters for victimized women are needed in order to prevent violence against women, in general, and promote the health and safety of pregnant women specifically.

\section{REFERENCES}

1. Rosenberg ML. Surveillance for suicide, homicide and domestic violence: strengths, weaknesses and issues. Public Health Rep. 1985; 100:593-595.

2. Bachman R, Saltzman LE. Violence Against Women: Estimates from the Redesigned Survey, National Crime Victimization Survey. Washington, DC: Dept of Justice, Bureau of Justice Statistics Special Report; 1995, NCJ-154348.

3. South Carolina Family Task Force. Violence in South Carolina Families. Columbia, SC: Dept of Health and Environmental Control; 1995.

4. Stark E, Flitcraft A, Zuckerman D, Gray A, Robinson J, Frazler W. Wife Abuse in the Medical Setting: An Introduction for Health Care Personnel. Washington, DC: Office of Domestic Violence; 1981. Monograph no. 7.

5. Sugg NK, Inui T. Primary care physician's response to domestic violence, JAMA 267(23):3,1573,160 .

6. Hillard PJ. Physical violence in pregnancy. Obstet Gynecol. 1985;66:185-190.

7. Bullock L, McFarlane J. The birthweight/battering connection. Am J Nurs. 1989;89: 1,153-1,155.

8. Helton AS, McFarlane J, Anderson ET. Battered and pregnant: a prevalence study. Am $J$ Public Health. 1987;77: 1,337-1,139.

9. McFarlane J, Parker B, Soeken K. Assessing for abuse during pregnancy: severity and frequency of injuries and associated entry into prenatal care.
JAMA. 1992;267:3,176-3,178.

10. Stewart DE, Cecutti A. Physical abuse in pregnancy. Can Med Assoc. J. 1993;149:1,2571,263 .

11. Centers for Disease Control and Prevention. Physical violence during the 12 months preceding childbirth-Alaska, Maine, Oklahoma and West Virginia, 1990-1991, MMWR. 1994;43:132-137.

12. Amaro H, Fried LE, Cabral H, Zuckerman B. Violence during pregnancy and substance use. Am $J$ Public Health. 1990;80: 575-579.

13. Berenson $A B$, Stiglich $N J$, Wilkinson GS, Anderson $A D$. Drug abuse and other risk factors for physical abuse in pregnancy among white non-Hispanic, black and Hispanic women. Am J Obstet Gynecol. 1991;64:1,491-1,496.

14. Campbell JC, Poland ML, Waller JB, Ager J. Correlates of battering. Res Nurs Health. 1992;15: 219-226.

15. Abbott J, Johnson R, Koziol-McLain J, Lowenstein SDT. Domestic violence against women : incidence and prevalence in an emergency population. JAMA. 1995;273(22):1,763-1,767.

16. Webster J, Sweelt S, Stolz TA. Domestic violence in pregnancy: a prevalence study. Med $J$ Australia. 1994;161:466-470.

17. Gazmarian JA, Adams MM, Saltzman LE, Johnson $\mathrm{CH}$, et al. The relationship between pregnancy intendedness and physical violence in mothers of 
newborns. Obstet Gynecol. 1995; 85:1,0311,038 .

18. Parker B, McFarlane J, Soeken K. Abuse during pregnancy: effects on matemal complications and birthweight in adult and teenagers women. Obstet Gynecol. 1994;84:323-328.

19. Norton LB, Peipert JF, Zieler S, Lima B, Hume L. Battering in pregnancy: an assessment of two screening methods. Obstet Gynecol. 1996; 85: 321-325.

20. Martin SL, English KT, Clark K, Cilenti D, Kupper L. Violence and substance use among North Carolina pregnant women. Am J Public Health. 1996; 86:991-998.

21. Walker L. The Battered Woman Syndrome. New York: Springer Publishing Co.; 1984.

22. Medicaid Policy and Procedures Manual (19931995) Chapter 20, OCWI Income Level, South Carolina Department of Social Services.

23. Poland ML, Ager JW, Olson JM. Barriers to receiving adequate prenatal care. $J$ Obstet Gynecol. 1987; 157:297-303.
24. Shah BV, Bamwell BG, Hunt PN, La Vange LM. SUDAAN User Manual, version 6.40. Research Triangle Park, NC: Research Triangle Institute; 1994.

25. Brooke GO, Anderson RH, Bland MJ, Peacock JL, Stewart MC. Effects on birthweight of smoking, alcohol, caffeine, socioeconomic factors and psychosocial stress. Br Med J. 1989;298:795-801.

26. O'Campo P, Gielen AC, Faden RR, Xue S, Kass N, Wang $M$. Violence by male partners against women during the childbearing year: a contextual analysis. Am J Public Health. 1995;85:1,092-1,097.

27. Gielen AC, O'Campo PJ, Faden RR, Kass NE, Xue $X$. Interpersonal conflict and physical violence during childbearing year. Soc Sci Med. 1994; 39:781787.

28. Crowell NA, Burgess AW. Understanding Violence Against Women. Washington, DC: National Research Council; National Academy Press; 1996. 